\title{
Pathological study of Hepatic coccidiosis in naturally infected rabbits
}

\author{
R. A.S AL- Naimi* \\ O. H. Khalaf * S. Y. Tano** \\ E. H. Al- Taee* \\ * Colle. of Vet. Med/ Unive. of Baghdad **Laser Institute/Unive. of Baghdad
}

\begin{abstract}
Thirty young domesticated rabbits (age 2-2.5 mo) of sexes showed clinical signs of anorexia, debilitation, diarrhea, icterus, rough hair coat and pendulous abdomen with hepatomegaly. Fecal samples were collected for demonstrated the presence of oocyts. Postmortem examination revealed presence of discrete yellowish-white nodules of $1 \mathrm{~mm}$ to 2 $\mathrm{cm}$ size on the surface and throughout the parenchyma containing a thick creamy white fluid. The histopathological changes showed biliary hyperplasia with different developmental stages of Eimeria stiedae in the epithelial cells, cholangitis and peribiliary fibrosis with newly formed bile ductules, severe congestion and dilation of central veins and sinusoids with disruption hemorrhagic areas. The hepatocytes showed degenerative changes to necrosis with areas of fibrosis and mononuclear cell aggregation, obstructive jaundice and a tendency to form oocyst granuloma. In conclusion hepatic coccidiosis lead to severe pathological changes both in bile ducts and liver parenchyma especially in young animals.

Key words: Coccidiosis. Eimeria. Rabbits.
\end{abstract}

\section{Introduction}

Coccidiosis is a common and worldwide protozoal disease of domestic rabbits but only rarely reported in other mammals (1). Kids are most susceptible; however, infected adults become carriers. There are 2 anatomical forms: hepatic caused by Eimeria stiedae (2), and intestinal caused by $E$. magna, $E$. irresidue, E. media, E. perforans, E. flavescens, E. intestinalis or other Eimeria species, transmission of both the hepatic and intestinal forms is by ingestion of sporulated oocysts usually in contaminated feed or water $(3,4)$. The oocysts of Eimeria steidae were first seen by Antoni Van-Leewenhoek in the bile of a rabbit in 1674 (5). The disease is a ubiquitous protozoan infection of animals seriously impairing their growth and food utelization (6). It causes significant

\section{Animals}

Thirty young domestic rabbits both sex (males and females) weighting 2$3 \mathrm{~kg}$ were kept in the Laser Institute for Higher Education for Experimental Studies. Rabbits were fed by concentrate and vegetable ad libitum, all the rabbits were found infected with $E$. stiedae as detected by fecal examination and postmortem examination. mortality in domestic rabbits $(7,8)$. Most of the researchs indicates that there is a strong relationship between the infection and the host age; they believe that the infection decrease with increasing age of the host (9). The coccidia of rabbits have not been studied to the same degree as the species which occur in other hosts. In Iraq there is a lack in information about this parasite; a few studies only were reported regarding the parasitological aspect of the disease $(10,11)$. No to our knowledge has attempted to show the effect of $E$. stiedae in liver tissue. Therefore, the aim of the study is to accomplish this task and study the pathological changes in affected livers. The results will increase our basic information on the current situation of this disease and for future researchs.

\section{Materials and Methods}

\section{Parasitological procedure:}

The symptoms of the naturally infected animals were recorded daily. The samples were then processed in the laboratory and examined by direct smear as well as saturated sugar flotation technique for the presence and identification of eimerian oocysts (12).

Histopathological procedure: 
Livers of the dead rabbits were thoroughly examined for the gross lesions and liver tissues were collected in $10 \%$ buffered formalin solution. Tissues were processed and 5-6 micrometer thick paraffin

\section{Results and Discussion}

\section{Clinical signs:}

The main clinical signs showed by the infected rabbits were depression, anorexia, brown watery diarrhea, emaciation, rough hair coat, pendulous and distended abdomen and hepatomegaly noted on abdominal palpation, progression weakness and death. Jaundice was also reported in 5 cases. The size and weight of livers of dead animals increased due to excessive proliferation of bile duct epithelium resulting in hepatomegaly which is characteristic of this disease leading to pendulous and distended abdomen. These results were agreed with $(14,10)$ stated that diarrhea, emaciation, and rough hair was due to infection of the intestine before the penetration of the sporozoites to the mucosa of small intestine and passing via the hepatic portal system to the liver to start the hepatic form (15).

Pathological Study:

\section{Gross Lesions:}

Hepatomegaly with irregular yellowish white nodules on the surface. (Figure1). Thick creamy white exudates from their cut surface, hepatic parenchyma was firm and gall bladder was distended. The peritoneal cavity showed increased dirty dull straw colored peritoneal fluid. The hepatomegaly was due to marked proliferation and distention of bile ducts forming nodules raised above the surface causing increase in secretion of mucous appeared as a creamy, white fluid on cut surface. The proliferated bile ducts cause damage to the liver parenchyma leading to post-necrotic scarring this explain, the firm consistency of hepatic parenchyma. These results agreed with $(14,16)$ that these lesions lead to disturbance of liver functions leading to decrease in $\alpha$ lipoprotein, glucose and proteins; in addition to increase in bilirubin in blood serum (17). embedded sections were cut for histopathological examinations after staining with hematoxylin and eosin (H\&E) according to (13).

\section{Histopathology:}

The lesions of the liver tissue sections of infected rabbits mainly confined to the liver and bile ducts consisted primarily of extensive hyperplasia of bile ducts. The bile ducts were markedly enlarged and lined by hyperplastic columnar epithelial cells thrown into multiple arborizing papillary fronds extending into the ductal lumina, resembling adenomatous hyperplasia with presence of developmental stages of the parasite (figure2). Numerous protozoal stages including microgametocytes, macrogameteocytes and oocysts were also seen (figure3). Other sections showed that the bile ducts were highly dilated with flattened epithelium having no or minimum projection to the lumen which are filled with numerous thin walled, ovoid oocysts (figure4, 5). The hyperplastic bile ducts were surrounded by large amount of fibrous connective tissue infiltrated with mononuclear cells (figure6). Furthermore, the ducts were filled with sloughed biliary epithelial cells. The hepatic parenchyma showed dilation and congestion of central veins and sinusoids with rupture of lining endothelial layer; in addition to vacuolar degeneration and necrosis of hepatocytes (figure7). The portal areas and liver parenchyma were infiltrated with mononuclear cells (figure8), severe hemorrhage in the necrotic area were also seen (figure9). Other areas showed the replacement of parenchyma with fibrous connective tissue infiltrated with mononuclear cells with a tendency to formation of newly formed bile ductules. Oocyst granuloma in which coccidial oocyst were observed in the central region were also noticed (figure10). In animals with jaundice their liver sections showed deposition of bile pigment in hepatic parenchyma (figure11). The present result 
showed that all animals were affected with the E. stiedae and that may be due to their younger age since it is almost known that hepatic coccidiosis which caused by E. stiedae is a primary disease of young rabbits (9). Coccidial infection is affected by the host age; The highest incidence was in 2-months rabbits and then the infection rate decreased as the age increased. The high level of susceptibility of infection in young rabbits may be due to their immune, feeding and reproductive status. This observation is consistent with the results previously reported $(18,19)$. This hepatic coccidiosis caused severe damage to the liver and it is more pathogenic in young rabbits and led to death among these animals (20). The proliferation of the bile duct epithelium might be due to the predilection and proliferation of the E. stiedae within the epithelium, whereas extensive dilation with little or no proliferation of bile duct epithelium might indicate the cell turn over which was also proved by the fact that these ducts contained more numbers of oocysts as compared to ones that had conspicuous proliferation. The wide spread sinus dilation, associated with

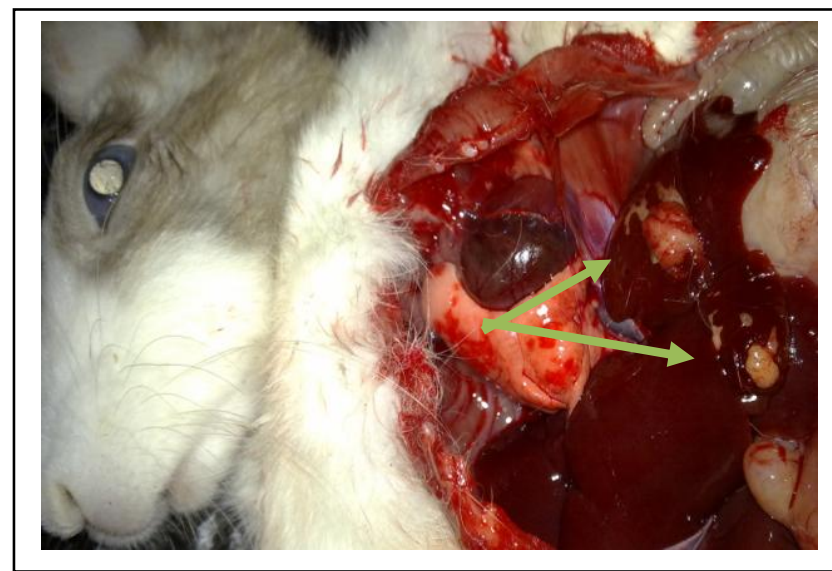

Figure 1: Gross lesion in the liver of rabbit infected with $E$. stiedae showing irregular yellowish white nodules on the surface $(\longrightarrow$ ). fibrosis in and around the cords might be attributed to the obstructed hepatic blood flow especially in the portal veins by immensely proliferating and dilating bile ducts. The stagnation of the blood flow would also result in hepatocyte cellular degeneration and atrophy of the cords. These histopathological observations are in agreement with those described by others $(21,14$, and 22). If the hepatic continuity of epithelium of bile ductules is broken the coccidian organism or oocyst would act as foreign bodies it might involve typical foreign body granuloma. (23) reported granulomatous hepatitis in coccidial infection in which coccidial oocysts were observed in central region of granuloma which later results in destruction and fibrosis of large area of hepatic lobules. The hepatic parenchyma showed areas of fibrosis with obstructive jaundice and that occurred due to massive necrosis of parenchyma leading to postnecrotic scarring. The bile pigment deposition was due to obstruction of the main ductal system from local swelling and jaundice is almost always present and that in agreed with previous studies (24, $14)$.

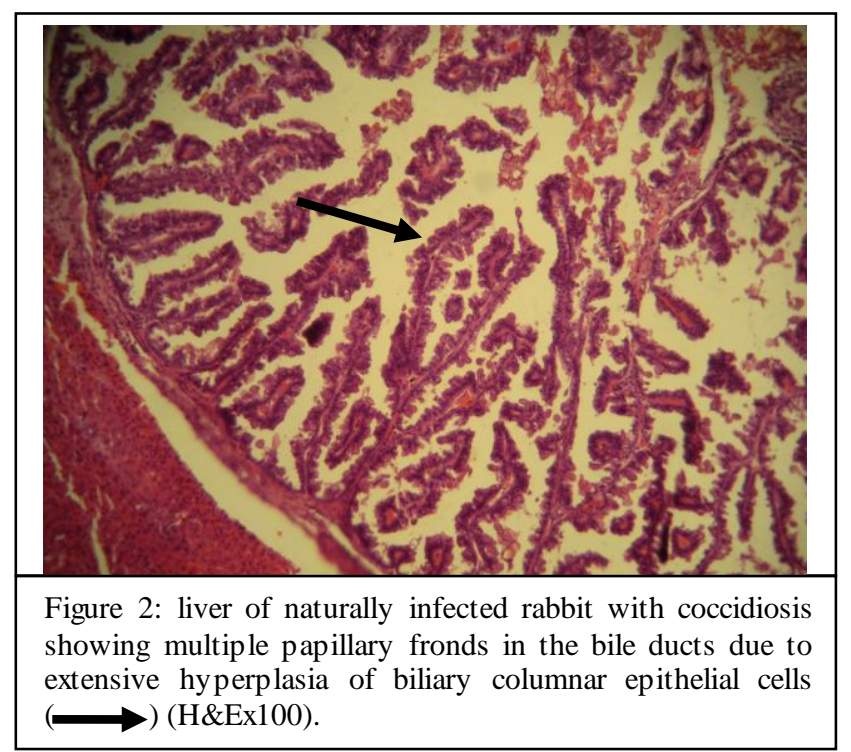




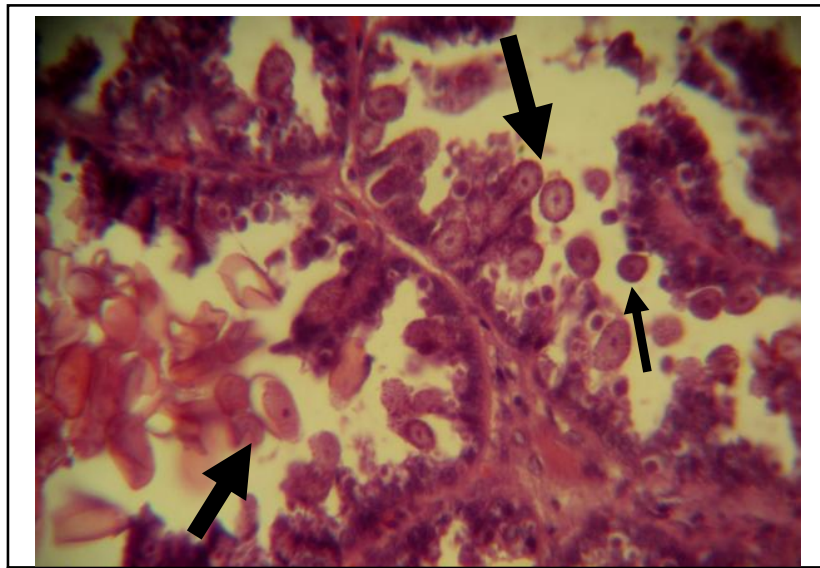

Figure 3: liver of naturally infected rabbit with coccidiosis showing different stages of the protozoal stages including microgametocy tes $(\longrightarrow$ ), macrogametocyts ( $\longrightarrow$ ) and oocyts $\longrightarrow$ (H\&Ex400).

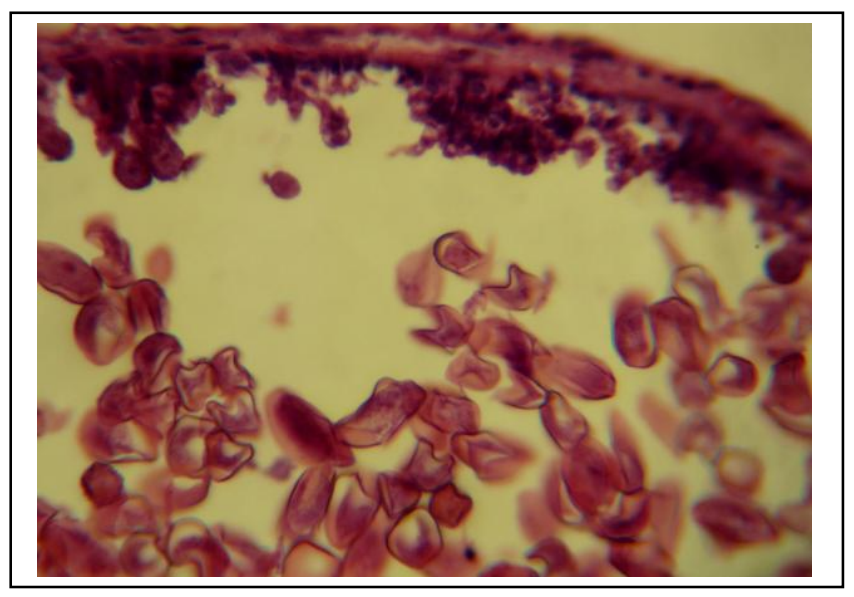

Figure 5: liver of naturally infected rabbit with coccidiosis at high magnification of the previous section (H\&Ex400).

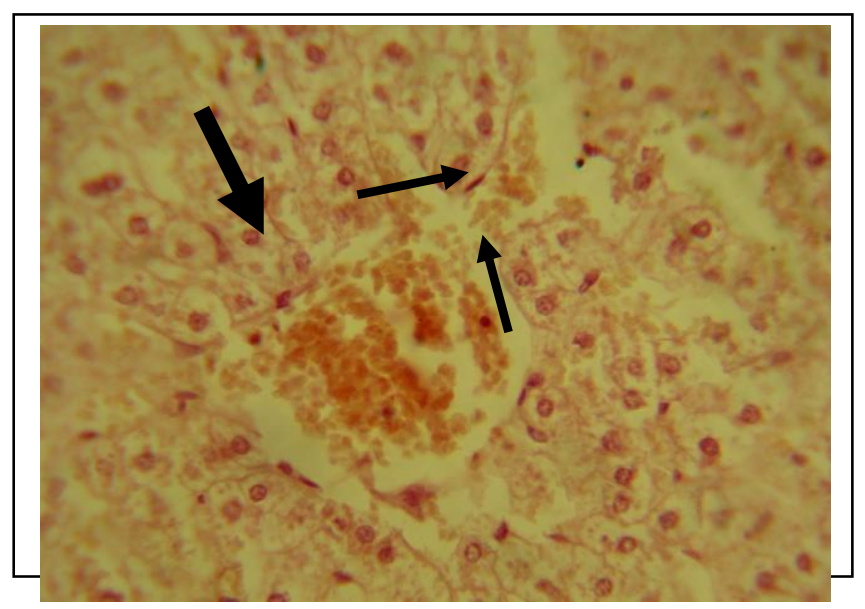

Figure 7: liver of naturally infected rabbit with coccidiosis showing dilation and congestion of central vein with rupture of lining endothelial cells $(\longrightarrow$ ) with vacular degeneration of hepatocytes (H\&Ex400).

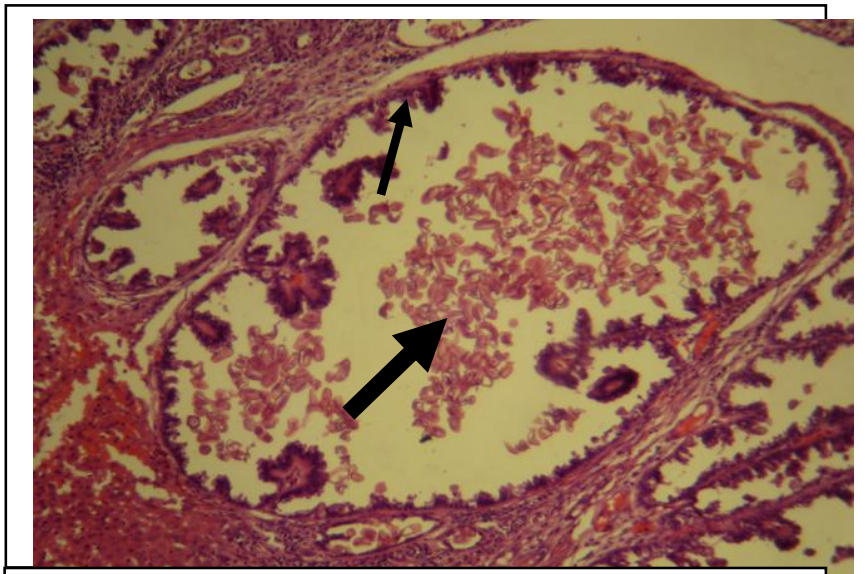

Figure 4: liver of naturally infected rabbit with coccidiosis showing bile ducts highly dilated with flattened epithelium having no or minimum projections to the lumen $(\longrightarrow)$ which are filled with numerous oocysts ( (H\&Ex100).

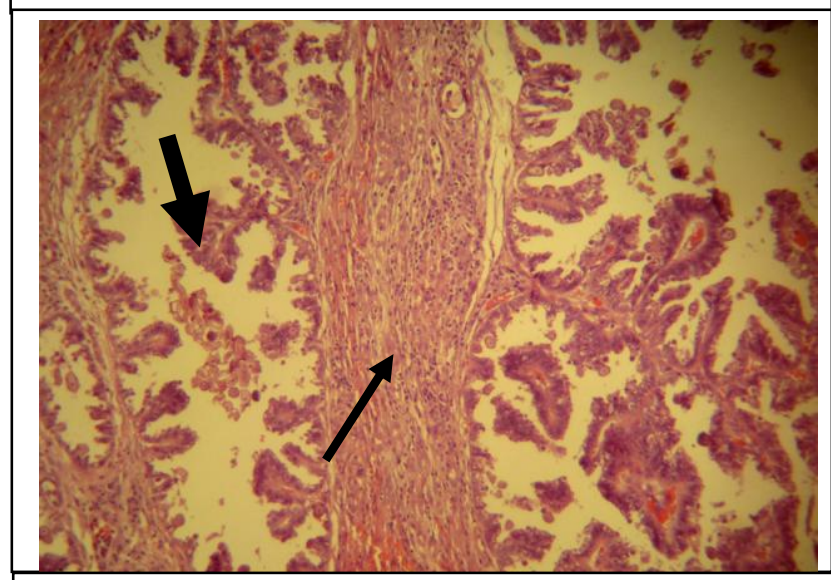

Figure 6: liver of naturally infected rabbit with coccidiosis showing peribiliary fibrosis with infiltration of mononuclear cells $(\longrightarrow$ ) and papillary projections of epithelium ) with different stages of the parasite (H\&Ex100).

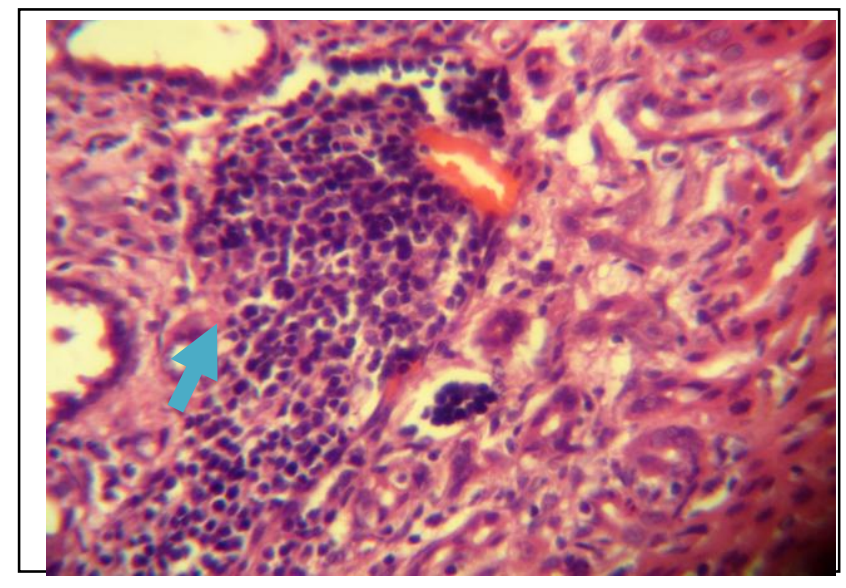

Figure 8: liver of naturally infected rabbit with coccidiosis showing focal infiltration of mononuclear cells infiltration within hepatic parenchyma (H\&Ex400). 


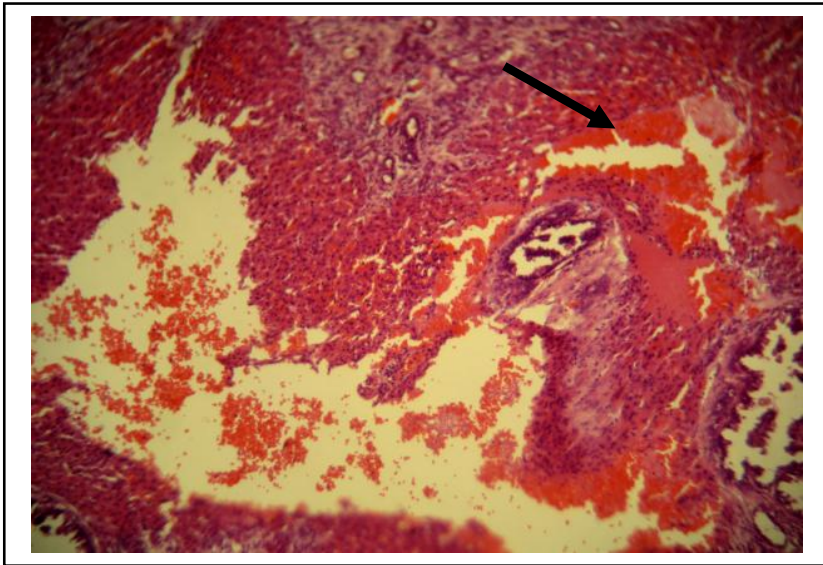

Figure 9: liver of naturally infected rabbit with coccidiosis showing severe hemorrhage $\longleftrightarrow$ ) within the necrotic area (H\&Ex100).

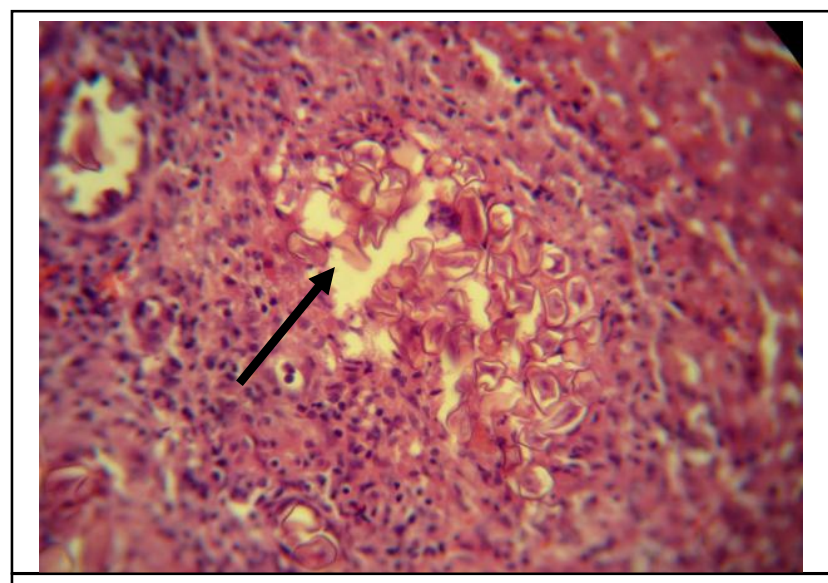

Figure 10: liver of naturally infected rabbit with coccidiosis showing oosyst granuloma within hepatic parenchyma (H\&Ex400).

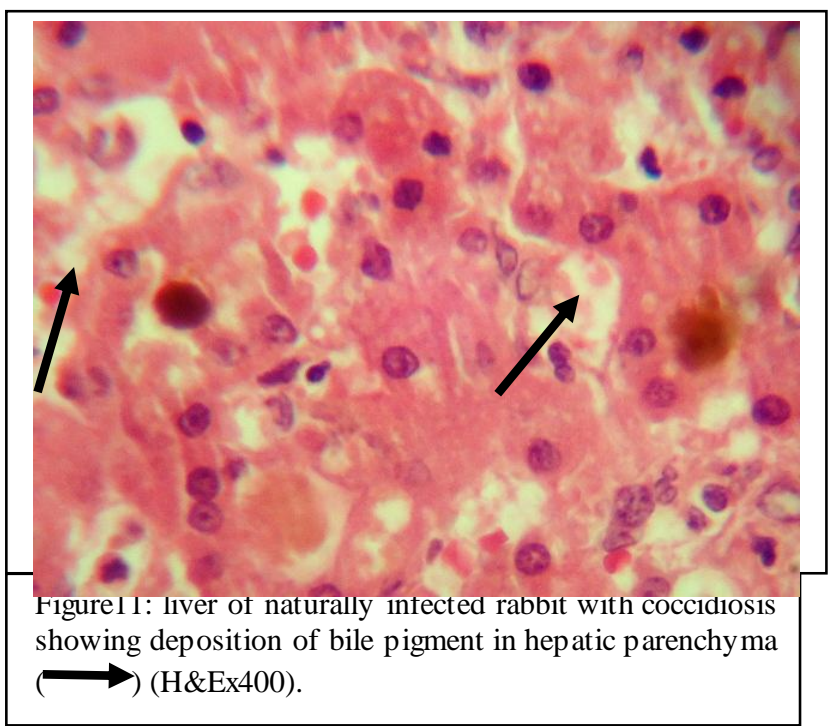

\section{References}

1. Wessels J.; Wessels M. E.; Wood R.; Quayle J.(2011). Hepatic coccidiosis in red lechwe (Kobus leche leche). Vet Record 168:338 doi: $10.1136 / v r . d 2191$.

2. Al-Rukibat, R. K., A.R. Irizarry. K. Lacey, K.R. Kazacos, S. T.(2001). Impression smears of liver tissue from a rabbit. Vet. Clin. Path., 30:57-61.

3. Yakhchall M.; Tehrani, A.(2007).Eimeriidosis and pathological finding in NewZeland white rabbits. J.Boil. Sci.,7: 1488-1491.

4. Oncel T.; Gulegen E.; Senlik B.; Bakirci S.(2011). Intestinal coccidiosis in Angora rabbits (
Oryctolagus cuniculus)caused by Eimeria intestinalis, Emeria perforans ands Emeria coecicola. YYU Veteriner Fakutesi Dergisi, 22(1)27-29.

5. Donald W. Duszynki; Steve J.Upton; Lee C. (2010). Taxonomic summary of genera within the Eimeride. University of New Mexico. Retrieved (8).

6. Abdel-Mageed, k.N.; N.M.Abu El-Ezz ; E.H. Abdel-Rahman (2005). Protective effect of Eimeria stiedae corporantigen against hepatic coccidiosis in rabbits. J. Egypt. Soc. Parasitol., 35(2): 581-595. 
7. Hanptman, K.; F.Tichy; Z.knotek (2001).Clinical diagnostics of hepatopathies in small mammals: Evaluation of importance of individual method. Acta Vet. Brno., 70:297-311.

8. El-Akabawy, L.M.; K. A. Zayan, AA. Tantawy, R.E.M. Omar(2004). Anticoccidial efficacy of propolis and Toltrazuril against Eimeria stiedae in New Zealand White rabbits. Zag. Vet. J., 32(1):122-145.

9. Wang, J.S; S.F.Tasi(1991).Prevalence and pathological study on rabbit hepatic coccidiosis in Taiwan. Proc. Natt. Sci. Counc. Repub. Chin. B., 15(14): 240-243.

10. Abbas, S.M (2009). Field study of some endoparasites in local rabbits. Proceeding of the ninth veterinary scientific conference. 1:157-160.

11. Yacoub A. Y; Abbas, S. M (2009). Field and experimental studies of Eimeria species in rabbits in Baghdad and Erbil provinces. 1: 161-166.

12. Soulsby, E.J.L (1986). Helminthes, Arthropods and protozoa of domesticated animals (Text Books). $8^{\text {th }}$ ed ., Williams and Wilkins company, London 657661.

13. Luna, L.G.(1968). Manual of histological staining methods of the armed forces institute of pathology. $3^{\text {rd }}$.ed .,Mcgrow-Hill book company New York.

14. Singla, L. D.; Juyal, p.D; sandhu, B. S.(200).Pathology and therapy in naturally Eimeria stiedae infected rabbits. J. Protozool . Res. 10, 185-191.

15. The Merck veterinary Manual (2011). Merck sharp and Dohme ., Corp, a Subsidiary of Merk and Co. Inc. WhiteHouse station, N J USA.
16. Al-Mathal B. M.(2008). Hepatic coccidiosis of the domestic rabbit Oryctolagus cuniculus domesticus L. in Saudi Arabia World J. Zool 3(1): 30-35.

17. Raymond, J. L.; Detrick, F.(2001). Pathology of rabbits. U. S Army Medical Research Institute of Infectious Disease. Raymonde det. Amedd. Army. Mil.

18. Hobbs, R.P.; L.E.Twigg; A. D. Elliot; A. G. Wheeler. ( 1999). Factors influencing the fecal egg and oocyst count of parasites of wild European rabbits Oryctolagus cuniculus (L) in southern western Australia. J. Parasitol, 85(5): 796-802.

19. Gres V. Voza T, Chaboud A.; Landaul .(2003).Coccidiosis of the wild rabbit (Oryctolagus cuniculus) in France. Parasitol. 10 (1): 5157.

20. Erdogmus, Z.S. and y. Eroksuz (2006). Hepatic coccidiosis in Angora rabbits. J. Anim. Vet. Advan ., 5(6):462-463.

21. Bhatia, B. B (2000). Textbook of Veterinary Parasitiology. $1^{\text {st }}$ ed. Directorate of Information and Publication of Agriculture, Indian Council of Agricultural Research, Krishi Anusandhan Bhavan, Pusa, New Delhi, 178180.

22. Rosmini, R., Simoni, P.(1979). Histological and ultrastructural features of hepatic coccidiosis in rabbits. Revista di Coniglicolture 16: 31-36.

23. Mehmoud, A.Z.; Ibrahim, M. K. (1989). Graunlomatous hepatitis in baldy rabbits associated with coccidial infection. Assuil. Vet. J. 21: 55-58.

24. Sanyal, P.K.; Sharma, S.C.(1990). Clinicopathology of hepatic coccidiosis in rabbits. Indian $\mathrm{J}$. Anim. Sci. 60: 924-928. 


\section{دراسة التغيرات المرضية لمرض الكوكسيديا في أكباد ألارانب المصابة}

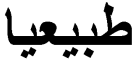

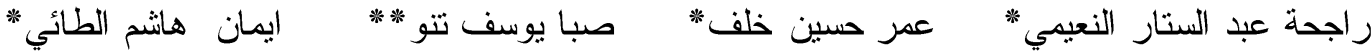

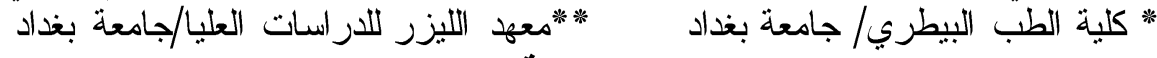

\section{الخلاصة}

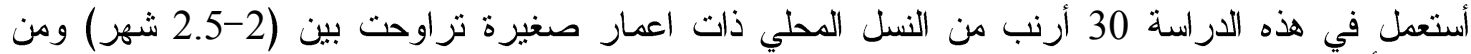

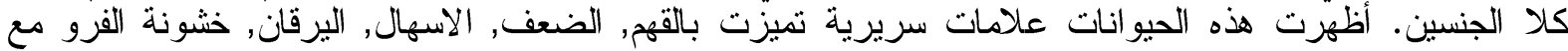

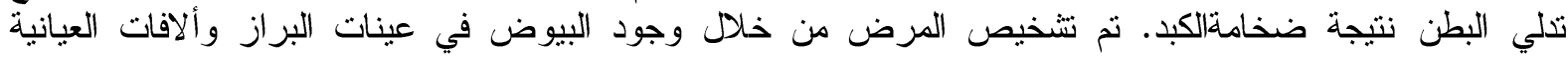

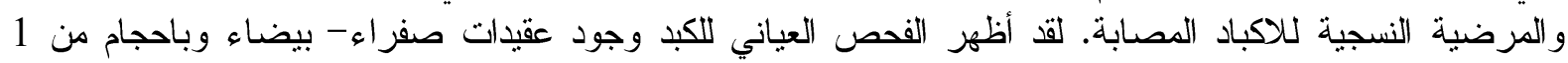

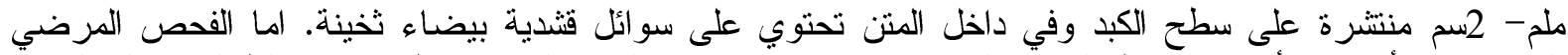

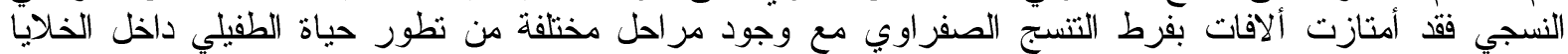

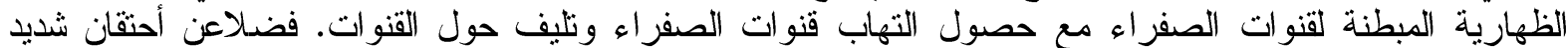
للاوردة المركزية والجيبانيات مع حصول تمزق في جدران الفية الاوردة المركزية مؤدية الى النزف النية الثنديد وحصول

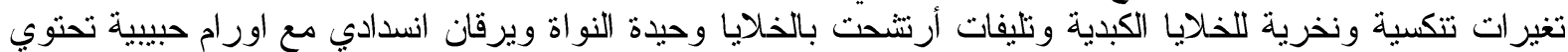

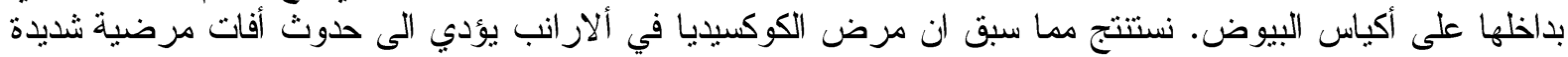
في قنوات الصفراء ومنت الكبد خصوصاً في الاعمار الصغيرة. مفاتيح الكلمات: مرض الكوكسيديا. الأيميريا. الأرانب. 